\title{
O PENSAMENTO PEDAGÓGICO DE GRAMSCI
}

\author{
Maria Elisabeth Blanck Miguel ${ }^{*}$
}

\section{Resumo}

O artigo busca, por meio de estudos do pensamento de Gramsci, bem como de Manacorda (1969), Macciochi (1980), Fiori (1979), Broccoli (1977) e Betti (1976), apreender o que é o "pedagógico" em Gramsci. Destaca o processo de construção de sua teoria conformada por suas experiências de vida, salientando-se a escola unitária, a educação como forma de elevar socialmente a população mais pobre a patamares superiores de cultura, 0 papel do intelectual orgânico e a própria organização da cultura. Apresenta indicações para a educação brasileira, especialmente para a formação de professores, decorrentes das reflexões sobre o pensamento gramsciano.

Palavras-chave: Educação, Pedagógico, Pensamento Gramsciano e Educação Brasileira.

\section{Resumé}

Cet article cherche par des études de la pensée de Gramsci, aussi bien que de celle de Manacorda (1969), de Macciochi (1980), de Fiori (1979), de Broccoli (1977) et de Betti (1976), appréhendent ce qu'il est le "pedagógique" chez Gramsci. Il détache le processus de la construction de sa théorie conformé par ses expériences de sa vie, mettant en accent l'école unitaire, l'éducation entant que forme l'élever socialement la population pauvre aux plateformes supérieures de la culture, le rôle de l'organisation intellectuelle et l'appropriation organique de la culture. Il présente des indications pour l'éducation brésilienne, particulièrement pour la formation des enseignents, issues des réflexions sur la pensée de Gramsci.

Mots-Clés: Éducation, Pédagogique, Pénsee Gramscienne et Éducation Brésiliense.

Quando retomamos os estudos sobre o pensamento "pedagógico" de Antonio Gramsci, pretendemos responder a duas perguntas: $\mathrm{O}$ que é mais precisamente o "pedagógico" no pensamento gramsciano? Quais seriam as diretrizes que poderiam ser retiradas do pensamento "pedagógico" de Gramsci, para nortear o trabalho em Educação, com relação à formação do professor?

Para encontrar as respostas às perguntas acima, guiamo-nos inicialmente por Manacorda, que na primeira parte da obra "O princípio educativo

* Prof.a/Pesquisadora do Programa de Mestrado em Educação da Pontifícia Universidade Católica do Paraná.

Email: blanck@rla01.pucpr.br 
em Gramsci", reproduz seu texto apresentado à Reunião Internacional de Estudos Gramscianos, realizada em Cagliari (abril de 1967) no qual comunicou estudos feitos sobre a "formação do pensamento pedagógico de Gramsci".

Em seguida buscamos em Gramsci, nos escritos de seus "Cadernos", a fonte principal de estudo.As impressões escolares de Gramsci certamente acentuaram a sua reflexão pedagógica quando mais tarde foram percebidas não como um problema individual, mas como realidade das crianças proletárias campesinas, uma vez que ele freqüentou quando criança e adolescente, escolas de pouca qualidade que não satisfizeram sua curiosidade intelectual. Ao escrever a seu filho Juliano, Gramsci afirmava: "O sistema escolar que segui era muito atrasado" (GRAMSCI, 1948. in MANACORDA, 1977, p. 17).

As recordações escolares do período de sua infância são da escola como instituição autoritária, discriminatória e que, muitas vezes, pela má qualificação de seus mestres, afogava os interesses infantis, como aconteceu com ele, que sentiu podadas suas inclinações para as ciências, porque seus professores do pequeno ginásio municipal de Santu Lissurgiu, não souberam orientálo, se é que perceberam no aluno tais inclinações.

As dificuldades escolares de Gramsci prosseguiram na juventude, não tanto pela má qualidade das escolas, mas sim pelas dificuldades financeiras em que ele vivia. Durante o Colegial, em Cagliari, não possuía todos os livros, e muitas vezes os tomou emprestados dos colegas ou dos professores. Além disso, as más escolas haviam-lhe causado deficiências de formação (escolar) que ele se via obrigado a superar.

As necessidades financeiras não tinham sua causa num período mais pobre pelo qual estaria passando a família de Antonio, mas sim eram provenientes das péssimas condições nas quais vivia o proletariado do sul da Itália: situação que era mais dramática ainda quando se tratava das populações camponesas que viviam em um estado de pauperismo e conseqüente alheamento dos acontecimentos políticos. Este alheamento tinha a ver também com 0 analfabetismo no qual estava mergulhada a classe pobre. A consciência desta realidade certamente contribuiu para que Gramsci, mais tarde, viesse a se interessar particularmente pelas questões educacionais, propondo a escola unitária como aquela capaz de, mediante um ensino eficiente, contribuir para retirar da ignorância as camadas mais pobres da população.

Quando Gramsci foi cursar a Universidade em Turin, suas dificuldades financeiras permaneceram, apesar da bolsa de estudos que conseguiu. Nesta época, sua formação recebeu dupla influência: Croce e Marx. Croce o influenciou com o idealismo e Marx com o materialismo dialético. Esta dupla influência seguiu durante um bom tempo, em Gramsci. O crocianismo se traduziu (segundo Manacorda) pelo modo idealista como ele (Antonio) compreendeu o socialismo, isto é, no sentido da rebelião social. No entanto, foi a prática política que exerceu em Turin, junto ao movimento operário, que o 
O pensamento pedagógico de Gramsci

colocou em contato com Marx. A compreensão do que é o marxismo só se completou quando mais tarde visitou e permaneceu em Moscou, já como representante do Partido Comunista italiano.

Quando interrompeu seus estudos universitários passou a colaborar mais efetivamente com dois jornais socialistas "El grido del popolo" e "Avanti". Nesta época apareceram, entre outros, os primeiros escritos sobre questões escolares, sempre vinculados aos temas do proletariado italiano. Assim é que a exigência da cultura para a classe proletária, bem como a necessidade de organização desta mesma cultura e também, "a busca de uma relação educativa que" "livrasse o proletariado da dependência dos intelectuais burgueses" (MANACORDA, 1977, p. 23), são os temas que, segundo Manacorda, começaram a aparecer nos escritos de Gramsci.

No "Grido", ele desenvolveu uma campanha para a renovação cultural e ideológica do partido socialista e propôs a organização de uma espécie de fórum, de debates (clube de vida moral), com seus colegas de militância política cujo objetivo era a renovação moral do partido. Nestas ocasiões seriam estudados e debatidos escritos de Lombardo Radice, Croce, Salvemini, Marx. A escolha dos autores demonstra bem que Gramsci ainda não havia se libertado do idealismo, embora lutasse no campo socialista. O que ele enfatizava então era a cultura como meio de luta política, isto é, como instrumento capaz de interferir no desenvolvimento econômico e político. Foi aí que Gramsci inseriu suas críticas "à escola, aos conteúdos escolares que eram classistas e burgueses e que excluíam os filhos da classe proletária, embora estes também fossem inteligentes e capazes, como escrevia no Avanti" (Ibid., p.26).

Estas reivindicações são, segundo Manacorda e Fiori, as mesmas que estão presentes em outros autores idealistas, e até mesmo em Gentile. Assim, as questões escolares colocadas por Gramsci neste período como a questão da escola clássica (da qual ele se mostrou um defensor com reservas, uma vez que ela não era extensiva à classe proletária), o ensino do latim (que para ele era um instrumento que ajudava a estudar o desenvolvimento histórico da sociedade romana em uma determinada época) são críticas, porém permanecem no plano teórico uma vez que os socialistas faziam a crítica da escola burguesa, mas não possuíam uma proposta mais concreta para a mesma.

Esta posição teónica ele tentou superar por suas atividades de organização cultural que o ajudavam a concretizar melhor o conjunto dos problemas e buscar as respostas. É esta prática de organização cultural que lhe permitiu perceber a necessidade da organização da cultura proletária mediante o trabalho do intelectual orgânico.

Não aparecem ainda neste momento a proposta de escola unitária e o trabalho como princípio pedagógico da mesma.

As propostas pedagógicas gramscianas acima citadas começam a tomar formas mais concretas enquanto ele organizava a sua prática política cul- 
tural sob a luz dos acontecimentos político-econômicos da Itália setentrional, em conjunto com as lutas que se desenvolviam na empobrecida Itália meridional e, ainda, das notícias sobre os fatos que ocorriam na Rússia (Revolução bolchevista) e que lhe chegavam censuradas.

Sua proposta pedagógica nasceu concretamente vinculada à uma proposta política: a da melhoria da sociedade como um todo mediante a melhoria das condições concretas de vida da classe subalterna. Esta proposta, no entanto, não é original, pois com tal conotação foram as propostas idealistas sobre a escola, principalmente aquelas que mais se aproximaram do socialismo, como as colocações de Radice e Salvemini. As denúncias de que a escola burguesa privilegiava as crianças desta classe já estavam presentes, sobretudo em Marx. $O$ que, provavelmente, contribuiu para que Gramsci chegasse a pensar numa proposta concreta de organização da cultura proletária (envolvendo as questões escolares e as do intelectual orgânico) foram as suas condições de vida e de prática política estimuladas pelas lutas operárias das quais participava e principalmente o contato com as experiências soviéticas que aconteciam na Rússia em todos os níveis (e logicamente também no educacional-escolar) para a construção do que pretendia ser a nova sociedade soviética.

A sua permanência naquele período, na Rússia, contribuiu para que superasse uma posição regionalista ou nacionalista e passasse a pensar em termos internacionais. Sua preocupação passava então a ser aquela relativa às questões do proletariado de todo o mundo, que ele identificava como questões comuns; Gramsci havia abandonado definitivamente as questões polêmicas de identificação entre o marxismo e positivismo ou o modo idealista com que justificava o marxismo (atitudes que marcaram a sua juventude). Agora a sua visão passa a ser aquela do marxismo atual de então, isto é, do marxismoleninismo.

Dentro desse novo contexto, como ficou a questão da cultura e da escola para a classe proletária que tanto havia preocupado Gramsci anteriormente?

Em conseqüência de suas experiências já não reivindicava para as classes subalternas a mesma escola humanista que possuíam os filhos da burguesia, mas passou a repudiá-la e a "recuperação crítica da instrução desinteressada só se fez muitos anos mais tarde"(Ibid., p. 48).

Novamente Gramsci pensou na organização da atividade cultural do proletariado, que propôs nas páginas do "Ordine-Nuovo".

Quanto à questão político-pedagógica, naquele momento ela se configurava pela preocupação em criar entre os trabalhadores e os intelectuais tradicionais a "comunidade de trabalho" (Id.) que parece ter sido uma experiência iniciada anteriormente e interrompida pelo fascismo.

A necessidade da relação com os intelectuais tradicionais foi manifestada na carta que escreveu a seu amigo Zino Zini $^{1}$ e tal colocação foi influen- 
ciada por Lenin que propunha construir a nova sociedade socialista "com os velhos ladrilhos capitalistas". ${ }^{2} \mathrm{E}$ também foi resultado do fato de haver presenciado parte das árduas experiências pedagógicas soviéticas, na tentativa de construir uma nova escola para uma nova sociedade no período de concretização da revolução bolchevista.

Em abril de 1922, ao fazer uma intervenção sobre a instrução profissional, no Congresso da Federação juvenil comunista, Gramsci denunciou um acordo entre "populares e socialistas para repartir-se a escola: para os primeiros as escolas médias superiores e os filhos da burguesia, para os segundos a instrução profissional e os filhos do proletariado"(Ibid., p. 49).

Porém Gramsci não ficou só na denúncia, mas foi além lançando a perspectiva de uma escola unitária cuja formação escolar se inspirava nos treinamentos dados aos operários, pelas fábricas. Ele se referia aos modelos de controle do trabalho intelectual (Gramsci vê a educação colaborando na indústria mas vê também a indústria como um elemento educativo: a produção disciplina o trabalhador e é portanto educativa).

É, neste momento, que Gramsci inicia concretamente a superação da postura idealista de reivindicação da escola humanista nos moldes daquela que era oferecida aos filhos da burguesia para as crianças proletárias e também de crítica da escola burguesa sem uma proposta concreta de sua substituição.

No entanto, a concretização desta nova posição só se fará nos anos de cárcere, quando nos seus escritos, principalmente no caderno 4 (XIII na numeração dada por Tatiana) que trata da "Organização da Escola e da Cultura" e da "Investigação do Princípio Educativo", coloca definitivamente seus princípios pedagógicos capazes de contribuir para se alcançar uma nova ordem, isto é, a "sociedade regulada" (como ele dizia) sob a hegemonia do proletariado.

As questões pedagógicas são retomadas por Gramsci somente em 1932 quando ele se propõe a organizar suas notas e relacionar os diversos temas que já havia escrito sobre os intelectuais.

Esta investigação, como já vimos, nasceu da preocupação com a organização da classe proletária italiana (embora ele já tivesse superado há muito tempo a visão parcial e regionalista) e estava contextualizada nesta realidade que se caracterizava pela hegemonia da burguesia conservadora e autoritária e que estava concretamente representada nos dois segmentos da sociedade italiana: o fascismo e a Igreja Católica.

Já anteriormente, Gramsci se preocupara com a união dos trabalhadores - intelectuais tradicionais (1922). Porém, agora (1932), mediante as leituras que lhe chegavam ao cárcere e refletindo sobre a função do intelectual na organização da cultura proletária, retoma este tema que dá origem a toda a sua proposta pedagógica. 
O contexto socioeconômico da Itália e do resto da Europa, nesta época, é caracterizado pelo desenvolvimento industrial e o industrialismo permeia todo o pensamento gramsciano dando os fundamentos de toda a sua proposta pedagógica para a elaboração do novo intelectual.

Este novo intelectual deveria ser capaz de promover "uma centralização e um impulso da cultura nacional italiana, que fossem superiores aos da Igreja Católica” (GRAMSCI, 1982, p. 127) e era importante não pelas suas atividades intrínsecas, mas pelo "conjunto geral das relações sociais, nas quais estas atividades se encontram"(Ibid, p.07). Este novo intelectual orgânico servirá de elo de ligação entre a infra e a superestrutura, entre dirigentes e dirigidos, deverá por um lado elaborar e difundir a ideologia e por outro "assegurar à classe uma certa homogeneidade e uma consciência de seu lugar na sociedade", segundo Macciocchi (MACCIOCCHI, 1980, p. 198).

Como seria possível desenvolver este novo intelectual?

É na educação técnica intimamente ligada ao trabalho industrial que ele vai identificar a fase de sua formação, porém não como ela (a educação) está colocada naquele momento na Itália, mas a partir da reorganização da educação e da cultura.

Ressurge então, porém com muito mais precisão, vigor e pertinência, a idéia da escola unitária, capaz de aderir à nova realidade, "escola única inicial de cultura geral, humanista, formativa" (GRAMSCI, 1982, p. 118) que equilibre o desenvolvimento da capacidade de trabalhar manualmente com 0 desenvolvimento da capacidade de trabalhar intelectualmente. "Deste tipo de escola única, por meio de repetidas experiências de orientação profissional, passar-se-á para uma das escolas especializadas ou para o trabalho produtivo" (Id).

Um dos pontos importantes relativos à educação escolar de então e que é captado por Gramsci é justamente a defasagem entre a escola tradicional, humanista e as novas necessidades da sociedade industrial. A antiga escola mostrava-se incapaz de fazer frente às novas necessidades, pois as atividades práticas haviam se tornado tão complexas e as ciências se mesclaram de tal modo à vida que determinaram a ineficácia da escola tradicional.

Na proposta da escola unitária de Gramsci estão contidos os principais fundamentos de sua pedagogia, ou seja, a escola estreitamente vinculada às necessidades socioeconômicas que naturalmente compreendem as político-culturais. Tais necessidades não se situam num plano genérico, porém são determinadas pelo contexto histórico-econômico e estão vinculadas a uma classe específica, isto é, ao proletariado.

O ensino a ser ministrado na escola elementar deverá ser aquele capaz de fazer frente à concepção folclórica do mundo que as crianças trazem porque a captaram do seu meio ambiente, e isto ocorre principalmente com as crianças mais pobres. Mediante o conhecimento objetivo das leis naturais que 
concorrem para a criação da sociedade dos homens, os alunos tornar-se-ão capazes de superar tal concepção e terão o ponto de partida para a compreensão da concepção histórico-dialética do mundo.

Porém este processo não é fácil e exige muita disciplina dos alunos, pois o estudo é também um trabalho muito fatigante, "um hábito adquirido com esforço, aborrecimento e mesmo sofrimento" (Ibidem, p.139) aos quais uma criança de família tradicional de intelectuais já está acostumada, mas à qual os filhos dos proletários terão dificuldades de se adequar pois identificam o cansaço apenas como aquele que provém de trabalhos manuais. Porém, numa nova situação (e aqui, como em todo o mais Gramsci pensa na sociedade socialista) tais questões poderão tornar-se muito difíceis, no entanto, far-seá mister superá-las.

A nova escola deverá ser organizada com vida coletiva diurna e noturna e o estudo será feito coletivamente com a assistência dos professores e dos melhores alunos, mesmo nas horas de trabalho individual.

Ela deverá garantir a presença dos elementos gerais que permitem o sucesso das crianças provenientes das camadas mais favorecidas da população: noções e aptidões que favoreçam a carreira escolar, como por exemplo, o conhecimento da língua literária.

Na realidade, a escola unitária será a escola verdadeiramente democrática, capaz de fornecer os fundamentos do desenvolvimento intelectual e manual, inclusive disciplinando intelectual e moralmente os alunos, elevandoos até que possam fazer suas escolhas profissionais.

Dizia Gramsci que a educação que transforma um operário manual em operário qualificado cria uma falsa mobilidade social e não é democrática mas estratifica as diferenças de classe; a educação realmente democrática tende a elevar os cidadãos, mesmo que abstratamente, para condições gerais de governar.

Para ele, o advento da escola unitária significava o início de novas relações entre trabalho intelectual e trabalho industrial, não só na escola mas também em toda a vida social.

É ainda nesta escola que vai se concretizar o princípio educativo do trabalho, que é na sua concepção, atividade teórico-prática capaz de superar a cisão entre educação e tarefa prática, educação e instrução.

O conceito e o fato do trabalho (da atividade teórico-prática) é o princípio educativo imanente à escola elementar, já que a ordem social e estatal (direitos e deveres) é introduzida e identificada na ordem natural pelo trabalho. O conceito do equilíbrio entre ondem social e ordem natural sobre 0 fundamento do trabalho, da atividade teórico-prática do homem, cria os primeiros elementos de uma intuição do mundo liberta de toda a magia ou bruxaria e fornece o ponto de partida para o posterior desenvolvimento de 
uma concepção histórico-dialética do mundo para a valorização da soma de esforços e de sacrifícios que o presente custou ao passado e que o futuro custa ao presente, para a concepção da atualidade como síntese do passado, de todas as gerações passadas, que se projeta no futuro (Ibidem, p. 14).

O princípio do trabalho vivido na escola unitária será aquele capaz de, pela compreensão e apreensão dos conteúdos escolares, fazer os alunos perceberem o movimento real existente no processo histórico.

Porém, a escola só é capaz de garantir que tal aconteça, através do trabalho pedagógico dos professores, se estes estiverem impregnados por esta filosofia. No entanto, diz Gramsci, os professores estão ligados ao alto grau de consciência da nação, da qual o corpo docente é tão somente uma expressão, ainda que amesquinhada, e não certamente uma vanguarda.

Após aprofundar o estudo no aspecto pedagógico do pensamento de Gramsci, já é possível procurar responder à primeira pergunta colocada no início do trabalho: O que é exatamente o "pedagógico" no pensamento gramsciano? tenha implícita.

O pedagógico em Gramsci transcende a educação escolar, embora a

Ao propor a formação dos intelectuais orgânicos do proletariado como capazes de reunir organicamente esta classe para buscarem conquistar e consolidar a hegemonia (da classe proletária) encaminhando-se para o desenvolvimento da sociedade socialista regulada, Gramsci está descobrindo na cultura uma possibilidade de contribuir para este desenvolvimento.

Sua proposta se fundamenta nos aspectos econômicos da sociedade que se concretizam no industrialismo e ele percebe que os homens, naquele momento e principalmente na Itália, ou pertencem à sociedade industrial e lutam para participar dos seus benefícios ou estão fora dela e permanecem envolvidos por um sistema semifeudal que os mantém presos ao analfabetismo e à ignorância.

Porém o industrialismo para Gramsci é o industrialismo socialista, do qual os trabalhadores possam se apossar e usufruir.

O eixo de conexão entre a produção industrial-material e a produção cultural é por excelência a escola, exercendo função pedagógica de transmissão da herança cultural no campo das ciências exatas, das ciências humanas, do domínio da língua, bem como na aquisição dos hábitos de estudo e da disciplina, necessários para a aquisição da cultura existente e produção de uma nova cultura.

Não somente a escola exerce a função pedagógica, mas também outras organizações são capazes de contribuir para a formação do intelectual orgânico (e mesmo para buscar a colaboração dos intelectuais tradicionais), assim é que ele pensa nas contribuições que podem ser dadas pela família, 
O pensamento pedagógico de Gramsci

pelas associações estudantis, associação de trabalhadores, sindicatos, jornais, organizações turísticas, entre outras.

Porém, o nexo pedagógico se faz mais evidente na escola, pois como diz Manacorda, em Gramsci "não apenas cultura e produção em geral, mas também escola e produção em particular são inseparáveis em uma perspetiva técnico-política, ou numa perspectiva do novo humanismo" (MANACORDA, 1987, s. p.).

Pois bem, o caminho que leva da técnica-trabalho ao novo humanismo da sociedade regulada passa pela técnica-ciência e por uma concepção humanístico-histórica que encontra uma das formas de realização pedagógica na relação professor-aluno e que acontece especialmente na escola.

Podemos então concluir que o pedagógico é, como ele mesmo disse em uma de suas cartas à sua esposa, uma relação que existe em toda a sociedade entre o grupo hegemônico e o subalterno, mas é também o nexo pelo qual é possível contribuir para a construção de uma nova sociedade na qual se realize uma nova hegemonia.

Este processo, molecularmente passa pela família e pela escola e nesta última acontece na relação pedagógica professor-aluno, quando então se realiza concretamente o princípio educativo do trabalho.

As reflexões sobre o que é o pedagógico no pensamento de Gramsci, nos remetem a algumas indicações sobre a formação de professores e que respondem à segunda pergunta feita no início: Quais seriam as diretrizes que poderiam ser retiradas do pensamento "pedagógico" de Gramsci, para nortear o trabalho em educação, com relação à formação de professores?

A afirmação gramsciana de que a realização do princípio educativo do trabalho depende do grau de consciência do professor com relação ao seu dever, bem como da compreensão filosófica do mesmo, mas que isto também depende "do grau de consciência civil da nação, da qual os professores são apenas uma expressão e não de vanguarda" (GRAMSCI, 1982, p. 131), nos leva a pensar que enquanto o grau de consciência civil da nação não se elevar, nada resta a fazer.

Porém, lembramo-nos de Marx quando ao discutir as questões relativas às mudanças das condições sociais afirmava que elas apresentavam dificuldades peculiares pois "por um lado, se exige uma troca das condições sociais para criar um sistema de ensino correspondente e, por outro lado, se exige um correspondente sistema de ensino para poder trocar as condições sociais. Por esta causa devemos partir da situação existente" (MARX, 1869 in MANACORDA, 1969, p. 98).

Também o próprio Gramsci partiu da situação existente na Itália naquele momento. Fazendo uma profunda e ampla análise do contexto situou a escola e as demais instituições socioculturais capazes de contribuir para a elaboração do novo intelectual, necessário para a construção da nova cultura. 
Levando sua análise até o âmago da escola, viu aí a importância do trabalho do professor; é mediante a ação do professor capaz de transmitir as noções científicas que o aluno vai substituir suas concepções mágicas do mundo e da natureza. A disciplina para o estudo, bem como as possibilidades de educação coletiva que podem ser exploradas pelo professor, e que certamente são ocasiões para que 0 aluno aprenda as noções de direitos e deveres, completam a educação escolar. Mas, é bom salientar, que isto só é possível mediante a ação do professor.

Para que ele assim proceda faz-se necessário que tenha consciência filosófica e política do seu dever, da importância da sua ação, em relação às classes menos favorecidas.

O professor que não tem tal consciência e também a competência pedagógica necessárias, isto é "um professor medíocre conseguirá que os alunos sejam mais instruídos, porém não mais cultos; pois o professor desenvolverá apenas a parte mecânica da escola e o aluno sendo um cérebro ativo terá que, com a ajuda do seu ambiente social desenvolver e organizar os conteúdos" (GRAMSCI, 1982, p. 132).

"Se o corpo docente é deficiente e o nexo educação-instrução" bem como "os problemas de ensino são resolvidos com esquemas no papel" (Id.) temos a escola retórica, sem seriedade, onde o certo não se concretizará como verdadeiro, pois este será apenas de palavra, isto é, retórico.

Estas reflexões de Gramsci são reflexões que também podem ser feitas em relação à formação de professores, e às políticas educacionais.

Finalmente, outra observação gramsciana é de importância para nossas reflexões; é aquela na qual ele se mostra surpreso quando vê que a escola espontaneista é louvada como democrática, quando na realidade apenas perpetua as diferenças sociais e salienta que a escola profissional para determinado grupo social tende a perpetuar as diferenças tradicionais.

Gramsci, mesmo dentro das paredes do cárcere sonhou com uma nova escola e uma nova sociedade. De nossa parte também queremos sonhar e tentar agir na concretização do sonho. Achamos que é possível.

Estas reflexões de Gramsci também podem ser feitas em relação à formação de professores. A necessidade de uma política orgânica que articule o conhecimento aprofundado dos conteúdos a serem ensinados e o modo de ensiná-los do conhecimento do aluno e sua necessidade de pleno desenvolvimento humano, bem como das novas solicitações da sociedade, precisam fundamentar-se na plena convicção de que a educação é um nexo articulador e promotor da cultura, auxiliando a elevar os alunos, ao menos em nível ideal, às condições de governantes, como queria Gramsci.

Antonio, mesmo dentro das paredes do cárcere, sonhou com uma nova escola e uma nova sociedade. De nossa parte também queremos sonhar e tentar agir na concretização do sonho. Achamos que é possível. 


\section{Notas}

1 Carta a Zino Zini, 02/04/1924, publicada em Rinascita, 21(1964)32 in Manacorda, M. A. p. 48.

2 Il marxismo e l'educazione I sobre todo Successi e difficoltà del podere sovietico, 202-207, y I compiti delle associazioni giovanili, 217-222 (respectivamente del 2 de octubre de 1920 in Manacorda, p. 49.

\section{Referências}

BETTI, G. Escuela, educación y pedagogia en Gramsci. Trad. J. A. B. Barcelona: Martinez Roca, 1976.

BROCCOL, Angelo. Antonio Gramsci y la educación como hegemonia. Trad. Fernando Mateo. México: Nueva Imagem, 1977.

FIORI, Giuseppe. A vida de Antonio Gramsci. Trad. Sérgio Lamarão. Rio de Janeiro: Paz e Terra, 1979.

GRAMSCI, Antonio. Os intelectuais e a organização da cultura. Trad. Carlos Nelson Coutinho. Rio de Janeiro: Civilização Brasileira, 1982.

MACCIOCCHI, Maria Antonieta. A favor de Gramsci. Trad. Angelina Peralva. Rio de Janeiro: Paz e Terra, 1980.

MANACORDA, Mário A. Marx y la pedagogia moderna. Barcelona: Oikos$\tan , 1969$.

Sigueme, 1977.

. El princípio educativo em Gramsci. Trad. Luis Legaz. Salamanca:

. Humanismo de Marx e industrialismo de Gramsci. Curitiba:

UFPR. (Palestra proferida em nov. 1987, mimeografado). 